\title{
FORMAS Y AMENAZAS DE LA OTREDAD. REPRESENTACIONES DESHUMANIZADAS DEL EXTRAÑO EN LA POESÍA ESPAÑOLA ACTUAL
}

\author{
Forms and Threats of Otherness. Dehumanized Depictions \\ of the Stranger in Spanish Poetry Today
}

\author{
María Ema Llorente, Universidad Autónoma del Estado de Morelos, México \\ Correo electrónico: emmall@uaem.mx
}

Recibido: $30 / 10 / 2020$

Aceptado: 23/06/2021

Publicado: 29/07/2021

\begin{abstract}
Resumen. El presente artículo se centra en el estudio de las representaciones de sí mismo como otro que aparecen en la poesía española actual. Esta otredad se manifiesta en los textos mediante entidades despersonalizadas o deshumanizadas, cuya presencia es percibida como un peligro que atenta contra la integridad del sujeto y amenaza con su aniquilación. Se propone el estudio de la otredad en relación con las figuras del extraño, el extranjero o el intruso. Para ello se utilizarán conceptos expresados desde la sociología, la filosofía y la antropología por autores como Žižek, Girard, Bauman y Graham. Partiendo del concepto de tensión inherente o brecha esencial, los poemas dan cuenta de la batalla interior del individuo por solucionar esta crisis, en textos que oscilan entre su constatación, su desarrollo o su superación, revelando, finalmente, que la idea de una identidad única, coherente y estable constituye tanto una necesidad o un deseo como una utopía.

Palabras clave: Identidad, tensión inherente, miedo a la extinción, deshumanización del extraño, doble monstruoso

Abstract. This paper focuses on the study of the representation of the self construed as other in current Spanish poetry. Such otherness is expressed in the texts through depersonalized or dehumanized forms whose presence is perceived as a danger undermining the subject's integrity and threatening to annihilate it. A study of otherness related to the figures of the stranger, the foreigner or the intruder is presented herein. Some sociological, philosophical or anthropological concepts expressed by authors such as Žižek, Girard, Bauman and Graham will be used for this purpose. Building on the concept of 'inherent tension' or 'essential lack', the poems account for the inner struggle of the individual in search for a solution to this crisis, in texts swinging between ascertainment, development or overcoming, and ultimately revealing that the idea of a single, consistent and steady identity is a need or desire, but it is also a utopia.
\end{abstract}

Keywords: Identity, inherent tension, fear of extinction, dehumanization of the stranger, monstrous double

Cómo citar: Ema Llorente, M. (2021). Formas y amenazas de la otredad. Representaciones deshumanizadas del extraño en la poesía española actual. EN-CLAVES del pensamiento, O(30), e438. doi: https://doi.org/10.46530/ecdp.v0i30.438

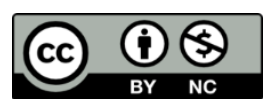




\section{Introducción}

El tema de la identidad y sus formas de representación textual constituye uno de los temas centrales y recurrentes de la poesía española contemporánea, ${ }^{1}$ tal como ya ha sido señalado por numerosos críticos. ${ }^{2}$ En múltiples textos y autores se representa un sujeto o una identidad en crisis, que refleja los cambios y alteraciones de la época actual.

Érika Martínez reflexiona sobre esta poesía señalando que quizá uno de sus rasgos más definitorios sea la aparición de un sujeto poético que se caracteriza por mostrar "una identidad en crisis" y por una tendencia a la "abolición de la propia subjetividad", en lo que ella misma califica como "una subjetividad construida en negativo". ${ }^{3}$

Además de los críticos, también los propios escritores coinciden al reconocer la preeminencia de este tema como uno de los contenidos o preocupaciones centrales de su escritura, tal como hace, por ejemplo, Eduardo García, uno de los autores que más insiste en el tratamiento poético de la identidad y sus formas de representación:

Mis poemas se sitúan en ese territorio de la identidad buscándose a sí misma, tratando de orientarse en el caos posmoderno. De ahí los juegos en torno al yo, que se escinde en vertiginosos desdoblamientos: el yo que escribe y el que brota de las palabras mismas del poema, el yo real presente y el que fue en la infancia o la adolescencia, el yo actual y el que podría haber sido y no fue... ${ }^{4}$

Como posibles causas de esta recurrencia temática pueden apuntarse tanto motivos generales —de carácter histórico, filosófico y sociocultural一, como motivos más específicos, referentes a la historia de la poesía en España y a su evolución en las últimas décadas.

En el primer caso, el tratamiento poético de la identidad en crisis puede verse como una consecuencia de la crisis general del individuo en la época posmoderna, caracterizada,

\footnotetext{
${ }^{1}$ Como marco temporal de este trabajo me centraré en la poesía publicada en España desde 1980 hasta la actualidad, escrita por autores nacidos alrededor los años sesenta, entre los que se encuentran Carlos Marzal, Eduardo García, Lorenzo Oliván, Vicente Valero, Ana Merino, Esther Jiménez y Fernando Valverde, entre otros.

2 Juan José Lanz, "La joven poesía española al fin del milenio: hacia una poética de la postmodernidad", Letras de Deusto (1995): 173-206; Luis Martín-Estudillo, "El sujeto (a)lírico en la poesía española contemporánea y su trasfondo barroco", Hispanic Review, 73, num. 3 (2005): 351-370.

${ }^{3}$ Érika Martínez, "Valores portátiles: el sujeto bajo crítica", en Luis Bagué Quílez y Alberto Santamaría (eds.), Malos tiempos para la épica. Última poesía española (2001-2012) (Madrid: Visor, 2013), 57-61.

${ }^{4}$ José Luis García Martín, La poesía figurativa: crónica parcial de quince años de poesía española (Sevilla: Renacimiento, 1992), 241.

www.enclavesdelpensamiento.mx

https://doi.org/10.46530/ecdp.v0i30.438
} 
como señala Juan José Lanz, en consonancia con el pensamiento de los autores señalados, por la disolución de la personalidad y la anulación completa de la conciencia individual. ${ }^{5}$

Esta disolución de la personalidad y anulación de la conciencia individual a la que hace referencia el crítico conduce a un nuevo concepto de identidad, entendida no de una forma estable o fija, sino flexible y cambiante; una identidad líquida, según la terminología de Zygmunt Bauman, a la que María Dolors Cuenca Tudela hace referencia en términos similares: "El sujeto no se pensará como sujeto transcendente, estable, indudable (en una sociedad en que el sujeto se vive como permanente cambio), sino como sujeto móvil, fluido, heterogéneo". A lo que añade lo siguiente: "En la postmodernidad se tiene la sensación de que los valores morales o religiosos ya no constituyen los cimientos fijos y estables sobre los que se construye un sujeto sólido, cosificado. El sujeto fluye inestable y cambiante". ${ }^{6}$

En relación con el segundo motivo, el que se refiere a la producción poética y a su evolución, no puede decirse que el tratamiento de una identidad problemática, fragmentada o escincida sea algo rigurosamente nuevo ni original en la poesía actual. Como señala Vicente Luis Mora: "En esta duda identitaria se debate gran parte de la mejor literatura mundial". ${ }^{7} \mathrm{Y}$ de igual forma, el tema del doble y sus variantes, una de las formulaciones más recurrentes de estos problemas de identidad, como señalan otros autores, constituye un tema que está presente en la literatura universal de todos los tiempos. ${ }^{8}$

En el caso de la poesía española contemporánea, y teniendo tal vez como referente la controvertida afirmación de Rimbaud —Je est un autre —, 9 la tematización de una identidad alterada puede rastrearse en autores como Antonio Machado, en la creación de sus heterónimos o complementarios, así como en múltiples de sus poemas; en Juan Ramón

\footnotetext{
${ }^{5}$ Lanz, "La joven poesía", 182.

${ }^{6}$ Dolors Cuenca Tudela, La ficcionalización del sujeto poético en la poesía española de la postmodernidad (Valencia: Universidad de Valencia, 1998), 143 y 145.

${ }^{7}$ Vicente Luis Mora, El sujeto boscoso: tipologías subjetivas de la poesía española contemporánea entre el espejo y la notredad (1978-2015) (Madrid y Frankfurt: Iberoamericana-Vervuert, 2016), 17.

8 José Bargalló (ed.), Identidad y alteridad: aproximación al tema del doble (Sevilla, Alfar, 1994).

${ }^{9}$ La frase de Rimbaud "Je est un autre", difundida después en multiples ocasiones, apareció en dos cartas escritas por el autor. La primera, la carta a Georges Izambard, fechada en Charleville, el 13 de mayo de 1871: "Je est un autre. Tant pis pour le bois qui se trouve violon, et Nargue aux inconscients, qui ergotent sur ce qu'ils ignorent tout à fait !' ["Yo soy otro. Tanto peor para la madera que se descubre violín, iy mofa contra los inconscientes, que pontifican sobre lo que ignoran por completo!']; y la segunda, la carta dirigida a Paul Demeny, fechada igualmente en Charleville, el 15 de mayo de 1871: “Car Je est un autre. Si le cuivre s'éveille clairion, il n’y a rien de sa faute. Cela m'est évident: j'assite á I'éclosion de ma pensée: je la regarde, je l'écoute..." "“Porque Yo soy otro. Si el cobre se despierta convertido en corneta, la culpa no es en modo alguno suya..."]. La evidente agramaticalidad de la expresión mencionada en estas dos cartas, incluidas después en las Cartas del vidente, manifiesta el estado interior y la profunda metamorfosis que el autor siente en esos momentos de transformación. Arthur Rimbaud, Iluminaciones. Cartas del vidente (Madrid: Hiperión, 1995), 96-201.
} 
Jiménez, en textos de Jardines Lejanos (1904) y Eternidades (1918); y en Luis Cernuda, en su adaptación y recreación de los tópicos simbolistas del hombre hueco y el traje vacío, por citar algunos de los autores más importantes del primer tercio del siglo XX.

En la producción poética más reciente, y en autores como los ya mencionados, la presencia recurrente de este tema puede apreciarse, entre otras muchas obras, en el significativo título de la antología editada por Josep María Rodríguez, Yo es otro: autorretratos de la nueva poesía, dedicada, precisamente, al tema del autorretrato y los problemas que plantea la representación del sujeto.

Del lado de la crítica, hay que destacar el estudio de Vicente Luis Mora, El sujeto boscoso. Tipologías subjetivas de la poesía española contemporánea (2016), en el que se ofrece un amplio y sustentado panorama de las posibilidades que presenta la poesía publicada en España entre 1978 y 2015 en relación con este tema.

En los textos poéticos, la crisis del sujeto y de su identidad se manifiesta de distintas formas, que oscilan, en la línea de las ideas y los conceptos negativos ya señalados, entre la indeterminación, la difuminación, la despersonalización, la división o la escisión y el descentramiento. ${ }^{10}$ Esto conduce a otros críticos a calificar esta identidad vacía o negada como "notredad". 11

La pérdida de la sensación de centro y la dificultad para hablar de o desde un sujeto unívoco, hace que, como señala Luis Martín-Estudillo, el yo lírico se expanda en su expresión hacia "lo otro", ${ }^{12}$ hacia una alteridad entendida tanto como algo ajeno y diferente a uno mismo como en relación a aquella alteridad que puede encontrarse dentro del propio yo.

Estas dos formas o posibilidades aparecen en los poemas, que recrean tanto una alteridad $\mathrm{u}$ otredad que se siente como parte del mismo yo de quien habla, recreando sensaciones interiores y subjetivas, en lo que podría verse como un movimiento o dirección de fuera hacia dentro; como una otredad objetivada, situada fuera del hablante, en un movimiento de dentro afuera.

Según esta idea, podría pensarse que los poemas representan o escenifican, a nivel interno e individual, situaciones que se están produciendo a escala social y colectiva en los grandes grupos humanos. El poema y los individuos que en ellos aparecen funcionarían, así, a modo de microcosmos, haciendo que lo que sucede en el interior de los textos pueda

\footnotetext{
${ }^{10}$ Martín-Estudillo, "El sujeto (a)lírico", 351-353.

${ }^{11}$ Mora, El sujeto boscoso, 293-303.

12 Martín-Estudillo, "El sujeto (a)lírico", 356.

www.enclavesdelpensamiento.mx

https://doi.org/10.46530/ecdp.v0i30.438
} 
verse como equivalente de lo que sucede fuera de ellos y viceversa; que las reflexiones que surgen a raíz del análisis de estos poemas y del "drama interno" que en ellos se representa puedan extrapolarse o ampliarse más allá de ellos.

Partiendo de esta idea, me centraré a continuación, dentro del ámbito literario en el que se enmarca este trabajo, en el análisis de algunos poemas de los autores mencionados, tomando en cuenta las ideas expresadas por autores como Amaia Izaola e Imanol Zubero y su caracterización de la figura del "extraño"; 13 Elaine Graham y sus ideas de "deshumanización" del extraño y disolución de la "singularidad humana"; ${ }^{14}$ Slavoj Žižek y su concepto de "tensión inherente";15 René Girard y su noción de "duplicidad monstruosa"; ${ }^{16}$ y, especialmente, Zygmunt Bauman y los conceptos de "identidad líquida" e "higiene ontológica", ${ }^{17}$ ideas que utilizaré como marco de referencia para el comentario de los poemas seleccionados.

\section{La figura del extraño y las representaciones deshumanizadas de la otredad}

La sensación de extrañeza y de extrañamiento ante uno mismo, así como la consideración de ser un desconocido o un "extraño" para el propio sujeto que se percibe, se revela como un tema recurrente en la poesía española actual, que se representa en los textos de diferentes formas.

En ellos, el sujeto poético observador se desdobla en objeto observado y se enfrenta a su identidad como una otredad. En los poemas, y según lo advertido, el otro es el que es diferente al uno, al que habla, y del que este se distancia, tanto espacial o temporalmente, como en naturaleza o en esencia. Este distanciamiento lleva asociada una jerarquía y una valoración, puesto que una de las identidades se considera la auténtica, la legítima o la verdadera y, por lo tanto, con derecho de permanencia, mientras que la otra es la infiltrada, la falsa o la invasora. Esta idea permite identificar esta figura con la del extranjero o el

\footnotetext{
13 Amaia Izaola e Imanol Zubero, "La cuestión del otro: forasteros, extranjeros, extraños y monstruos", Papers, 100, núm. 1 (2015): 105-129.

${ }^{14}$ Elaine Graham, Representations of the Post/Human: Monsters, Aliens and Others in Popular Culture. New Jersey: Rutgers University Press, 2002.

${ }^{15}$ Slavoj Žižek, Visión de paralaje (Buenos Aires: FCE, 2006).

${ }^{16}$ René Girard, La violencia y lo sagrado (Barcelona: Anagrama, 1983).

17 Zygmunt Bauman, La postmodernidad y sus descontentos (Madrid: Akal, 2001), e Identidad (Madrid: Losada, 2005). 
extraño, tal como la estudian la antropología y la sociología, construida sobre la noción de distancia y diferencia de lo familiar, lo cercano y lo conocido. ${ }^{18}$ Según esta concepción, la categoría del extraño, una de las categorías con la que las ciencias sociales se han aproximado al problema de la otredad, ${ }^{19}$ implica la idea de límite y frontera, tanto de manera espacial y geográfica como metafórica, algo que también resulta relevante en el caso de las formulaciones poéticas. Como ya se adelantó, en muchos poemas el espacio del cuerpo resulta asimilable al espacio geográfico y político, y en su interior tienen lugar procesos similares a los que ocurren fuera de éste. Zygmunt Bauman se refiere a la noción del extraño utilizando precisamente una metáfora o una comparación espacial para definir la cualidad de aquello que está “fuera de lugar". ${ }^{20}$

Esta idea de límite resulta importante porque es aquello que contiene y separa la identidad propia y la protege de la figura de ese extraño que se considera un invasor y que se siente como una amenaza. En los textos, la presencia o la convivencia con el otro se experimenta de manera negativa y angustiosa, pues el otro es alguien o algo que impide el reconocimiento, la identidad y la unidad de uno mismo, y constituye un peligro para la integridad y la permanencia. El miedo proviene de la posibilidad de perder los límites, borrarse, dejar de ser, fundirse con el otro o con lo otro y desaparecer. Los textos manifiestan así esa mixofobia o miedo a la confusión o la hibridez identitaria, que puede relacionarse también con esa crisis de la "singularidad humana" [human uniquenes] a la que hace referencia Graham, que se caracteriza, precisamente, por el "emborronamiento de los límites" y la disolución de la "higiene ontológica" con la que a lo largo de los últimos tres siglos nuestra cultura ha trazado las líneas que separan a los seres humanos de la naturaleza y de las máquinas. ${ }^{21}$ Lo que se teme es, en este sentido, como se verá, la pérdida de la humanidad, por lo que una gran parte de las manifestaciones de la otredad que aparecen en estos poemas se representa mediante elementos y rasgos no humanos, en un proceso de despersonalización o deshumanización del individuo.

La presencia o la irrupción de estas formas extrañas provoca así un desorden o una desestabilización a la que el sujeto debe enfrentarse, que da lugar a una lucha o una batalla por el dominio de una de las dos identidades sobre la otra.

\footnotetext{
${ }^{18}$ Izaola y Zubero, "La cuestión del otro", 114.

${ }^{19}$ Ibid., 107.

${ }^{20}$ Bauman, La postmodernidad, 14.

${ }^{21}$ Graham, Representations of the Post/Human, 11.

www.enclavesdelpensamiento.mx

https://doi.org/10.46530/ecdp.v0i30.438
} 
Esta idea de la lucha y el enfrentamiento entre las partes me parece fundamental, y se mantiene como una constante o un eje estructurador en la mayoría de los poemas seleccionados, que coinciden en ese aspecto de violencia, agresión y ferocidad. Todos los poemas elegidos representan o escenifican, así, una "épica silenciosa" o una "sorda lucha", palabras con las que se define esa tensión constante entre el sujeto y el otro o lo otro en el poema "Imagen en televisión", de Lorenzo Oliván, que describe precisamente el acto de la contemplación perpleja de uno mismo mediante la expresión "un extraño mirándose extrañado". ${ }^{22}$

La idea de lucha o enfrentamiento del sujeto consigo mismo puede relacionarse, además, con la idea de "tensión inherente" expresada por Žižek, ${ }^{23}$ entendida como la representación de un conflicto interno. ${ }^{24}$ Como aclara Mora: "En el sistema de Žižek la brecha o fractura no es ajena al sujeto, no le viene dada desde fuera, y tampoco, en buena parte, es algo que se produce a posteriori de su nacimiento; en realidad, es constitutiva, puesto que no existe una dualidad primordial, sino sólo la brecha inherente al uno". ${ }^{25}$

Esta brecha, fractura o escisión es, según Žižek, algo consustancial al ser humano, aunque otros autores la consideren como algo histórico y la atribuyan a los cambios ocurridos durante la modernidad y la posmodernidad. El mismo Mora alude a esta "doble dimensión de la fractura", que hace de ella algo tanto permanente como temporal. En palabras de este autor, se trataría, por un lado, de una "cualidad desgarrada consustancial al hombre y, por lo tanto, tan paradigmática como culturalmente arquetípica allá donde pongamos la vista", y, por otro, de una escisión "constitutiva del sujeto moderno y posmoderno". ${ }^{26}$

En cualquier caso, ya se trate de una tensión inherente o histórica, esta fractura o esta brecha interior sería la responsable de esa lucha del individuo, que intenta solucionarla ejerciendo una violencia contra sí mismo, que se manifiesta de diversas formas:

[La tensión inherente] Admite la situación de lucha interna entre ellas, su tensión hacia/ contra lo unitario, de modo que es una cabal representación de las formas de violencia que el sujeto [sobre todo, el sujeto escritor] ejerce contra sí mismo, en aras de solucionar su

\footnotetext{
${ }^{22}$ Lorenzo Oliván, Puntos de fuga (Madrid: Visor, 2001), 67.

23 Žižek, Visión de paralaje.

${ }^{24}$ Mora El sujeto boscoso, 74.

25 Ibid., 76.

${ }^{26}$ Ibid., 27.

www.enclavesdelpensamiento.mx

https://doi.org/10.46530/ecdp.v0i30.438
} 
fractura interior, reconocerla [sea mediante la aceptación o la parodia] o desarrollarla hasta la total separación identitaria. ${ }^{27}$

Reconocimiento, desarrollo o solución de la fractura podrían proponerse así como las tres posibilidades con las que se encuentran los autores y de las que los poemas seleccionados ofrecen distintas variantes, en la recreación de momentos puntuales o parciales de un proceso mayor o general, tal como se verá en las páginas siguientes.

\section{Reconocimiento de la otredad amenazante}

Un primer estadio o una primera variante en la representación textual de la otredad lo consituye el reconocimiento y la expresion del extrañamiento de sí mismo, que se manifiesta en los poemas mediante afirmaciones o declaraciones explícitas del hablante.

El poema "Otro", de Javier Rodríguez Marcos, cuyo significativo título evidencia el tema central de la composición, constituye un buen ejemplo de esta sensación de amenza, inestabilidad y precariedad que caracteriza al sujeto representado en estos textos.

Acorde con las figuras mencionadas, y recreando una ambientación bélica coherente con estas ideas, el hablante del poema confiesa haberse dejado "invadir" por la presencia de un otro desconocido e indeterminado "alguien, cualquiera, otro". La inestabilidad que esta invasión provoca y la sensación de precariedad que la acompaña se materializa a través de elementos como una casa en ruinas, un animal que acecha y un ser desconocido que adquiere el perfil del invasor, el usurpador o el burlador:

En mi cuerpo

-me he dejado invadir-

se levanta una casa con los cristales rotos

que amenaza ruina,

se esconde un animal

que espía mis movimientos.

Alguien. Cualquiera. Otro.

Me persigue y se viste con mi ropa,

piensa mis pensamientos

juega con mi memoria como un niño

la deja por el suelo, destrozada,

como un cacharro inútil. ${ }^{28}$

\footnotetext{
${ }^{27}$ Ibid., 77. Las cursivas son del original.

${ }^{28}$ Javier Rodríguez Marcos, "Otro", en Josep María Rodríguez (ed.), Yo es otro: autorretratos de la nueva poesía (Barcelona: DVD, 2001), 35-38.

www.enclavesdelpensamiento.mx

https://doi.org/10.46530/ecdp.v0i30.438
} 
Una idea similar se recrea en el poema "Autorretrato en un tren camino de Coimbra", de Martín López Vega. En este caso, el desconocimiento de uno mismo da lugar a la aparición de una otredad cifrada en términos de un abismo creciente, que supone nuevamente una amenaza para la integridad del sujeto y provoca su progresiva desaparición:

Yo no sé quién soy Insisto Tampoco pienso detenerme a pensarlo

Pues siento cómo dentro de mí crece el abismo Cómo yo mismo me voy desvaneciendo ${ }^{29}$

La percepción de la presencia de esa otredad adquiere matices más angustiantes en la sospecha de que el otro o el extraño puede ser, en realidad, uno mismo, o de que los dos sean una misma cosa. Se borra así la diferencia entre lo exterior y lo interior, mostrando que las dos variantes o posibilidades apuntadas por Martín-Estudillo, la de la otredad que se proyecta hacia el exterior y la que se recrea como parte del propio yo, pueden verse, en cierto modo, como la misma.

Un ejemplo de esta identificación del que habla con aquello que se teme aparece en el poema "El pozo salvaje", de Carlos Marzal. En este poema, lo desconocido y lo amenazante adquieren la forma de un pozo que alberga abominaciones y extrañas criaturas y que acaba revelándose, según declaraciones del hablante que se expresa mediante la forma de un tú desdoblado, como el mismo individuo que lo contiene:

hay un pozo salvaje al fondo de ti mismo, un lugar que es tan tuyo como tu propia muerte.

En sus aguas dudosas

reposa desde siempre lo que no está dormido, un remoto lugar donde se fraguan las abominaciones y los sueños, la traición y los crímenes.

Es el pozo de lo que eres capaz y en él duermen reptiles, y un fulgor y una profunda espera.

Es tu rostro también, y tú eres ese pozo. ${ }^{30}$

\footnotetext{
${ }^{29}$ Martín López Vega, “Autorretrato en un tren camino de Coimbra”, en Rodríguez, Yo es otro.

${ }^{30}$ Carlos Marzal, "El pozo salvaje", en José Carlos Mainer (ed.), El último tercio de siglo: antología consultada de la poesía española (1968-1998) (Madrid: Visor, 1999), 746.

www.enclavesdelpensamiento.mx

https://doi.org/10.46530/ecdp.v0i30.438
} 
En este caso, la idea de amenaza se sugiere mediante la alusión a lo "latente", expresado mediante la perífrasis "lo que no está dormido", que es también, por lo tanto, potencia y capacidad o posibilidad de acciones negativas: "abominaciones", "traición” y "crímenes". Todas estas sensaciones se sitúan en una ambientación tenebrosa que resulta acorde con la noción del "lado oscuro" o doble monstruoso, como se verá más adelante. En este lugar pantanoso habitan también animales que resultan coherentes con este escenario, los reptiles, que al igual que el resto de elementos negativos, se encuentran dormidos.

La presencia del reptil como amenaza aparece también finalmente en el poema "La ansiedad", de Fernando Valverde, en el que el animal, que también habita en el corazón del individuo, se recrea en una faceta más activa o más agresiva, en lucha por recuperar su lugar original: "Tengo en el corazón un reptil que me araña/ tratando de volver a sus piedras azules". 31

En los ejemplos anteriores, y mediante frases como "en mi cuerpo", “dentro de mí”, “al fondo de ti mismo" o "en el corazón”, puede verse cómo lo extraño y lo ajeno se sitúan dentro del individuo. La otredad es todavía una parte menor, integrante de una totalidad mayor o abarcadora, qué irá ganando dimensión e importancia en estadios posteriores de este proceso de extrañamiento, tal como se verá en los siguientes apartados.

\section{Desarrollo de la tensión. Intercambio de roles y otredad monstruosa}

En otros casos, la otredad se manifiesta como una variante externa de uno mismo, en lo que podría considerarse una dirección o un movimiento de dentro hacia afuera.

En este estadio, la idea no es ya la de la invasión o la metaforización de sensaciones de extrañamiento y alteridad que se sienten en el interior del cuerpo, sino el cambio radical o esencial que se percibe en la identidad del hablante y su conversión en otra cosa. En muchos casos, este cambio se representa mediante una inversión. Si en el estadio anterior el otro era el invasor agresivo y el hablante la víctima pasiva, ahora se invertirán los papeles y las jerarquías, y el protagonista del poema se percibirá a sí mismo como el que creía que era el otro, el extranjero o el extraño. Según el escenario bélico en el que se sitúan muchos

\footnotetext{
${ }^{31}$ Fernando Valverde, "La ansiedad", en Los ojos del pelicano (Madrid: Visor, 2010), 58. www.enclavesdelpensamiento.mx https://doi.org/10.46530/ecdp.v0i30.438
} 
de estos poemas ya comentado, estos roles se manifiestan frecuentemente mediante las figuras del cazador y la presa. Esta caracterización aparece de forma explícita en un poema de Eduardo García, que elige para representar la otredad la escisión entre escritor y personaje, o entre el ser biográfico o empírico y el textual, identificando a cada uno de ellos con una de las figuras mencionadas:
Alzo la mano. Estoy
a punto de tocarle tan despacio,
tan infinitamente cerca, aquí, debajo de mi voz, en el espacio que media entre la espada y la pared.
Al descubrir su cara lo comprendo.
Yo soy mi cazador, yo soy la presa; yo soy quien me sonríe en la penumbra.
Nos separa un papel y sin embargo no podré cruzar nunca ese desierto. ${ }^{32}$

Además de este fragmento, donde la identificación con estas figuras se produce de manera explícita, los poemas "El lobo" y "El bosque", de Fernando Valverde, pueden servir también para ejemplificar esta idea de la inversión. En el primero de ellos, y continuando con la idea de la "deshumanización", la presencia extraña se representa mediante la forma de un lobo, animal que simboliza la amenaza y la ferocidad por excelencia, que se sitúa, igual que en el texto anterior, en el interior del poema:

Dentro de este poema pasa un lobo que deja sus pisadas en la nieve.

Sigiloso y hambriento, recorre una ciudad que miró confiada hacia el futuro.

Hoy han bajado todas las persianas.

Es tarde, trato de no hacer ruido y que avancen los versos como pasan los días para que el lobo escoja un camino que lleve a otro lugar, una presa más débil.

Pero en este poema espera un lobo

\footnotetext{
${ }^{32}$ Eduardo García, No se trata de un juego (Granada: Diputación Provincial de Granada, 2004), 74. www.enclavesdelpensamiento.mx https://doi.org/10.46530/ecdp.v0i30.438
} 
que ha venido a buscarme.

Aunque intente estar quieto y no hacer ruido

salta por las palabras un recuerdo

que me arranca un aullido y me devora. ${ }^{33}$

En este caso, la idea de amenaza se sugiere mediante la caracterización del lobo como cazador "sigiloso y hambriento" que busca una presa, razón por la que el hablante trata de "no hacer ruido" y "estar quieto", intentando despistar a ese animal que "ha venido a buscarme" y que termina, en este caso, por consumar su búsqueda. Sin embargo, antes de devorar a su presa, el lobo le "arranca un aullido", palabra con la que se sugiere que el propio hablante es también un lobo, o, mejor dicho, que es el propio lobo al que se teme y del que se intenta huir sin éxito.

De forma similar, en el poema "El bosque", del mismo autor, se produce tambien una inversión o un intercambio de roles, pues el bosque que representa la amenaza para quienes se internan en él resulta ser, igualmente, la misma persona que habla en el poema. Este salto se sugiere en el texto de manera sutil y progresiva, mediante la traslación que se produce entre los deícticos iniciales, primero "allí", "allí en el bosque", que implica distancia, y finales, "de mí", que indica cercanía respecto al hablante, o, en este caso, identificación con él, como se declara de manera explícita en el verso final del poema: "aunque el bosque sea yo y alguien huya de mí":

Alguien entra en el bosque mientras grito.

No puedo detenerlo.

Sólo existe mi voz

tan rota y tan cobarde

que cada noche vuelve a repetirse

sin que logre hacer nada.

Hay tanta incertidumbre allí en el bosque, es tanta su espesura, que es mejor estar quieto, aunque la misma angustia suceda cada noche, aunque el bosque sea yo y alguien huya de mí. ${ }^{34}$

Con la mención de la palabra "grito" al inicio de poema, se sugiere ya, de entrada, la sensación de miedo y amenaza que es constante en estos poemas y que se subraya con el avance de esa presencia indeterminada que vuelve cada noche, emanada de la espesura del bosque, de la que nuevamente se intenta escapar sin éxito.

\footnotetext{
${ }^{33}$ Fernando Valverde, "El lobo", en Los ojos del pelícano, 64.

${ }^{34}$ Fernando Valverde, "El bosque", en Los ojos del pelícano, 47. 
La misma idea de la coincidencia de las dos identidades se insinúa en el breve poema “Acantilado", de José María Micó, en el que de nuevo se igualan observador y observado: "Fondo que miro como mira un hombre/ que desea caer, y no se tira,/ porque se espeja dentro del abismo". ${ }^{35}$ La tensión inherente e irresoluble que se manifiesta en estos poemas se cifra en este caso en términos de esa contradicción entre lo que se desea y lo que realmente se hace. Mientras el abismo se presenta como la otredad amenazante, es al mismo tiempo algo que se anhela, pues ofrece también la posibilidad de resolución de un conflicto que, sin embargo, como en la mayoría de estos poemas, se perpetúa o se mantiene.

El intercambio de roles y la evolución o la sorpresa final del texto constituyen también el mecanismo compositivo del poema "Laberinto", de Julio Martínez Mesanza, que sigue de cerca el texto "La casa de Asterión", de Borges, y que ofrece una resolución final similar. ${ }^{36}$ En el poema de Martínez Mesanza, el ser para quien el hablante declara haber mandado construir un laberinto es el minotauro, ese "monstruo" al que se hace referencia en tercera persona. Sin embargo, la afirmación final de poema permite una doble interpretación, debido a la ambigüedad de la frase "mi corazón conocerá el descanso", que hace pensar, teniendo en mente el texto de Borges mencionado, no sólo en el descanso provocado por la muerte del monstruo ajeno, sino en el descanso derivado de la propia muerte del hablante, que queda, así, identificado con el minotauro:

He ordenado trazar un laberinto de muros elevados e inasibles $\mathrm{y}$ he mandado encerrar en sus tinieblas a un monstruo que hace tiempo alimentaba:

De noche me despiertan los opacos alaridos de víctima y verdugo.

$$
\text { ..... }
$$

Me dicen que vendrá un hombre sin patria y que penetrará en el laberinto, buscando sin terror su oscuro centro: cuando la espada hiera al monstruo infame, mi corazón conocerá el descanso. ${ }^{37}$

Este tipo de recreaciones muestran, así, tanto el miedo a la propia identidad, al lado desconocido u oscuro de uno mismo, miedo a "ser" el otro, con la consecuente inversión de

\footnotetext{
35 José María Micó, Caleidoscopio (Madrid: Visor, 2013), 30.

${ }^{36}$ Jorge Luis Borges, El Aleph (Buenos Aires: Losada, 1949).

37 Julio Martínez Mesanza, "Laberinto", en Juan Cano Ballesta (ed.), Poesía española reciente (1980-2000)

(Madrid: Cátedra, 2001), 163-164.

www.enclavesdelpensamiento.mx

https://doi.org/10.46530/ecdp.v0i30.438
} 
jerarquías y categorías que esto supone; como el miedo a que los límites se borren y a fundirse o confundirse con aquello a lo que se teme de manera permanente. Se trataría de un estadio más avanzado de la inversión, que se expresa en los poemas mediante la idea de la transformación o la metamorfosis. En estos casos, la conversión en otro o en otra cosa se manifiesta de manera evidente u objetiva, mediante la transformación física del cuerpo. Lo importante aquí, en relación con el tema de este trabajo, y al igual que en los otros poemas, es la sensación de amenaza, miedo y angustia que esta transformación provoca en quien la padece, que es también, al mismo tiempo, quien la relata.

En algunos textos, esta transformación es solamente pasajera o temporal, y se presenta bajo la forma de una pesadilla de la que se puede despertar, recuperando la forma original. Es lo que ocurre en el poema "Jarrón vacío", de Pelayo Fueyo, en el que el hablante aparece identificado con un objeto que se siente ajeno y extraño, como es un jarrón, que se relaciona de alguna manera con la idea del pasado y la infancia perdida, tema central de la composición:

Yo era el jarrón que ahora reposa en la consola, en manos de aquel niño que no nos conoció. En mi boca insertaba flores de especies raras, como el que recorriese un jardín encantado y quisiese dejar testimonio del hecho.

Me he despertado de ese como de cualquier sueño.

Ahora el jarrón reposa intacto en la consola, y yo he recuperado mi forma primitiva: de aquella pesadilla ya nos hemos librado. Pero nunca ese niño que soñaba entusiasta, porque es extraño a mí tanto como ese sueño, como extrañas las flores son al jarrón vacío. ${ }^{38}$

En otros casos, cuando no se ofrece la posibilidad del regreso tranquilizador a una situación inicial, el miedo o la angustia proceden precisamente de que la situación sea permanente, lo que supondría, como se mencionó, el peligro de la desaparición o la extinción del hablante. Muchos de estos poemas muestran de esta forma la experiencia de este proceso de cambio, vivido o percibido de manera angustiosa por el protagonista, identidad original que se siente suplantada por la otra.

\footnotetext{
${ }^{38}$ Pelayo Fueyo, "Jarrón vacío", en Luis Antonio de Villena (ed.), La lógica de Orfeo: antología (Madrid: Visor, 2003), 136. 
Como un ejemplo de esta idea puede mencionarse el poema "Casi una rapsodia bohemia", de Esther Jiménez. En este poema, la hablante parece irse transformando en un animal nocturno, un murciélago o tal vez un vampiro, por continuar con la caracterización monstruosa, que, igual que en los otros casos, hace evidentes las dudas y el miedo en relación a la propia identidad:

Empiezo a ver de noche. Los insectos se vuelven hacia mí, van hacia mí los pájaros nocturnos. En Madrid hay un constante ruido de murciélagos;

sus alas no son más que sendos brazos, me digo, pienso y digo que hasta aquí mamífera de noche me dormí colgada alguna vez. Y que he volado.

Confundo los abismos con las sombras: unos me siguen y otras me suicidan ${ }^{39}$

En este poema, los cuerpos de la persona y el animal se confunden de manera progresiva. La hablante "empieza a ver de noche", al tiempo que percibe las alas de los murciélagos de una manera familiar o cercana como "brazos". Lo que en un principio es sólo una sospecha o una intuición, va aumentando, en una angustia creciente que revela esa presencia constante de los “pájaros nocturnos", que conducen a la transformación final, ocurrida en un día concreto: “mamífera de noche me dormí/ colgada alguna vez", lo que otorga la facultad imposible: "he volado". En una ambientación semejante a la del poema "Otro", comentado páginas atrás, la hablante confunde "abismos" y "sombras", elementos negativos que de nuevo representan la idea de la persecución amenazante y de la extinción: unos "me siguen” y otras “me suicidan".

Finalmente, el poema "Vida de lagartija", de Ana Merino, omite el proceso de la transformación para centrarse en su resultado. En este poema quien habla es directamente una lagartija, animal que expresa ahora sus miedos ante la amenaza de los otros:

Yo quise ser animal casero con vistas a la playa pero soy lagartija y habito entre las grietas de una roca volcánica en medio del desierto. .....

La vida es un enigma del que sólo descifro un trozo de esperanza,

\footnotetext{
${ }^{39}$ Esther Jiménez, "Casi una rapsodia bohemia", en Jesús Munárriz (ed.), Veinticinco poetas españoles jóvenes (Madrid: Hiperión, 2003), 394.

www.enclavesdelpensamiento.mx

https://doi.org/10.46530/ecdp.v0i30.438
} 
lo miro de reojo y nunca me detengo

porque temo el acecho de los tirachinas

o la sombra de un gato. ${ }^{40}$

En este estadio del proceso, las dos identidades se hacen equivalentes e igualan sus posiciones o su valoración. Ya no se trata de una identidad legítima y una falsa o invasora, sino que ambas están al mismo nivel, e incluso resultan intercambiables o se presentan como versiones recíprocas de una misma cosa.

Las transformaciones y metamorfosis enlazan en este punto con representaciones del monstruo y de lo monstruoso, figura extrema de la otredad que desvela la fragilidad de las categorías que damos por supuestas y que tiene, como señala Graham, capacidad para “desestabilizar nuestras certidumbres axiomáticas". ${ }^{41}$ Como mencionan en este sentido Izaola y Zubero:

La monstruosidad indica el final de las delimitaciones claras, un mestizaje caótico de categorías que, en pleno proceso de confusión, nos advierten de que su ordenamiento está muy lejos de ser inevitable. [...] Los monstruos simbolizan una grieta en una categorización que pensábamos y queríamos inviolable; [...] y es en esta capacidad donde reside su horror. $^{42}$

Y continúan los autores más adelante:

El monstruo sintetiza el tabú y el deseo, los límites y su transgresión, son repulsivos y fascinantes a la vez: Los monstruos simbolizan, entonces, no el otro opuesto sólidamente encerrado tras sus propios límites, sino la otredad de unos mundos posibles, de posibles versiones de nosotros mismos, no realizadas aún. ${ }^{43}$

También Girard hace alusión a la idea de la reciprocidad entre el yo y el otro, el doble y el monstruo, y menciona, en este sentido, que "no hay doble que no esconda una monstruosidad secreta", y, de la misma manera, que "no hay monstruo que no tienda a desdoblarse". ${ }^{44}$ El monstruo manifestaría así la intensificación de un proceso de alteridad u otredad no reconocida, como el mismo pensador declara:

Bajo el término doble monstruoso alineamos todos los fenómenos de alucinación provocados por la reciprocidad ignorada, en el paroxismo de la crisis. El doble monstruoso

\footnotetext{
${ }^{40}$ Ana Merino, "Vida de lagartija”, en De Villena (ed.), La lógica de Orfeo, 216.

${ }^{41}$ Graham, Representations of the Post/Human, 39.

${ }^{42}$ Izaola y Zubero, "La cuestión del otro", 121.

${ }^{43}$ Ibid., 122.

${ }^{44}$ Girard, La violencia y lo sagrado, 166.

www.enclavesdelpensamiento.mx

https://doi.org/10.46530/ecdp.v0i30.438
} 
surge ahí donde se encontraban en las etapas anteriores un "Otro" y un "Yo" siempre separados por la diferencia oscilante. ${ }^{45}$

Además de los casos ya mencionados, la representación de la otredad de una forma monstruosa aparece en numerosos poemas contemporáneos, entre los que puede incluirse, por ejemplo, el poema "Los monstruos nunca mueren", de Carlos Marzal, que ejemplifica claramente esta idea:

Los monstruos nunca mueren.

Si crees que retroceden, si parece que han olvidado el rastro de tus días, tus lugares sagrados, tus rutinas, el bosque inabarcable de tus sueños; si sonríes, porque ya no recuerdas la última noche en que te atormentaron, ten por seguro que andarán buscándote, ten por seguro que darán contigo.

Los monstruos nunca mueren.

Viajan dentro de ti, regresan siempre. ${ }^{46}$

A pesar de los intentos por solucionar esa brecha interior, el poema confirma nuevamente que esa solución no es posible, puesto que la escisión es constitutiva del individuo. Lo que se manifiesta es entonces esa idea de amenaza constante, semejante a ese estado de latencia que se describía en el poema "El pozo salvaje", del mismo autor, cuya culminación finalmente se confirma: "andarán buscándote” y "darán contigo".

\section{Separación y ruptura. La higiene ontológica}

\section{y la utopía de la identidad unitaria}

En los poemas analizados en los apartados anteriores puede verse cómo los textos ofrecen distintas variantes o estadios en los intentos de resolución del conflicto de la tensión o brecha inherente del individuo. Este proceso puede incluir la culminación o el desenlace final temido, o bien detenerse antes de llegar a este momento. Poemas como "No se trata de un juego", de Eduardo García; "Vida de lagartija", de Ana Merino; o "El bosque”, de

\footnotetext{
${ }^{45}$ Ibid., 171. Las cursivas son del original.

${ }^{46}$ Carlos Marzal, "Los monstruos nunca mueren”, en Mainer (ed.), El último tercio de siglo, 748. www.enclavesdelpensamiento.mx https://doi.org/10.46530/ecdp.v0i30.438
} 
Fernando Valverde, plantean el problema de la otredad y de su amenaza y, o bien se detienen en el punto culminante de esta tensión, o constatan su circularidad o su recurrencia. Otros poemas ofrecen algún tipo de solución al conflicto, pues presentan la angustia y la amenaza como algo temporal o pasajero, que se resuelve solo, como es el caso del primer poema analizado, "Otro":

Sucede y de repente - es la única ventaja-, sin detenerme a contemplar mi estado, la batalla, los muertos, los heridos, cierro los ojos y desaparece. ${ }^{47}$

De igual manera, el poema "El jarrón vacío" muestra, como ya se vio, la metamorfosis como una "pesadilla" de la que el hablante despierta. En otros poemas, sin embargo, la transformación resulta permanente, como en "Casi una rapsodia bohemia", de Esther Jiménez. Por último, otros textos se muestran más pesimistas y presentan el final de un proceso que concluirá con la temida desaparición. En el poema "Autorretrato en un tren camino de Coimbra”, de Martín López Vega, ya citado, el hablante adelanta en tiempo futuro lo que le ocurrirá, que es, irremediablemente, igual que en muchos otros casos, su disolución o su desaparición:

Pues siento cómo dentro de mí crece el abismo Cómo yo mismo me voy desvaneciendo

Y no creáis que me apena Pues de nuevo habitante de la Nada

volveré a encontrarme con todos aquellos que quise y me quisieron

Fantasma yo también en un mundo de fantasmas ${ }^{48}$

Finalmente, el último estadio de estos intentos de resolución es, como señalaba Mora, la separación total de las dos partes o las dos facetas de la identidad, aspecto que se recrea en poemas como los de Ana Merino y José Micó.

En el primero de ellos, perteneciente a $L a$ voz de los relojes, la otredad no se representa ya en términos subjetivos o internos, como en otros poemas, sino objetivos, es decir, ya no es una sensación o una percepción del hablante, sino que constituye una "realidad" textual. En el poema se relata el desdoblamiento o la escisión de la protagonista, cuyo cuerpo se separa en dos mitades. Una de las partes, la que conserva el corazón, se ha

\footnotetext{
${ }^{47}$ Rodríguez Marcos, "El Otro", en Rodríguez (ed.), Yo es otro, 54-55.

${ }^{48}$ Martín López Vega, "Autorretrato en un tren camino de Coimbra”, en Rodríguez (ed.), Yo es otro, 35-38. www.enclavesdelpensamiento.mx https://doi.org/10.46530/ecdp.v0i30.438
} 
quedado inmóvil, puesto que es, como se declara al final del poema, la parte "suicida", mientras que la otra debe aprender a moverse y a caminar en su nuevo estado, resistiéndose a morir, algo que consigue instalando un reloj en el lugar en el que se encontraba originariamente el corazón, en un nuevo ejemplo de cosificación o deshumanización:

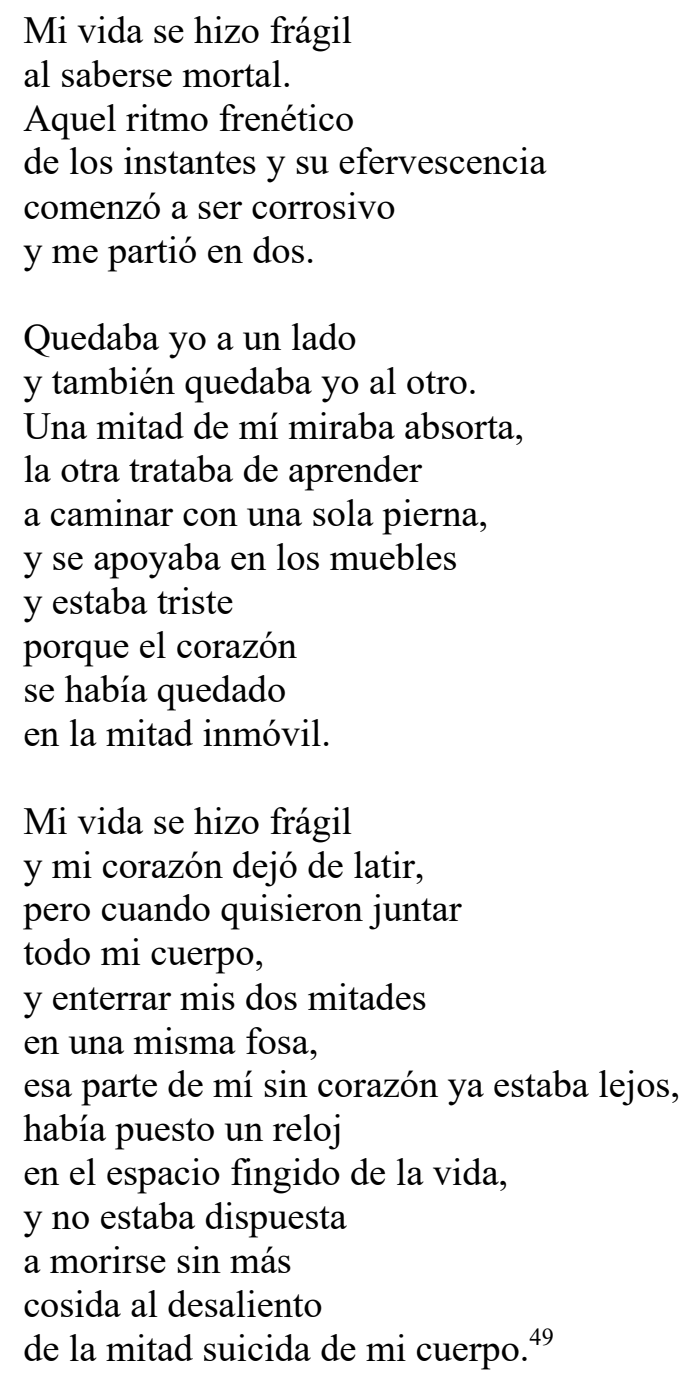

Un ejemplo semejante lo ofrece el poema "Fuera de mí", de José María Micó, que resulta ya bastante explícito en su título. En este poema, el hablante habla de sí mismo como si se tratara de otro, refiriéndose en tercera persona a ese "hombre que está en pie/ por una combustión que él no ha encendido". Esta sensación de extrañeza se intensifica aludiendo a la idea de otros seres, en este caso los perros de una jauría interior, que animan desde dentro el cuerpo de quien habla, concebido de una forma mecánica y nuevamente deshumanizada como un "torpe mecanismo":

\footnotetext{
${ }^{49}$ Ana Merino, "Mi vida se hizo frágil...”, en De Villena (ed.), La lógica de Orfeo, 207-208. www.enclavesdelpensamiento.mx https://doi.org/10.46530/ecdp.v0i30.438
} 
Si estoy fuera de mí, ¿qué me sostiene?

¿Qué jauría interior corre y boquea

Para erguir este torpe mecanismo

De huesos y de músculos? $?^{50}$

Se trata de un caso extremo de enajenación y otredad en el que el sujeto declara estar "fuera" de sí, preguntándose o extrañándose, igual que en el poema anterior, por la continuación de la vida de su cuerpo.

Los ejemplos anteriores, así como otros ejemplos similares, hablan de una identidad escindida y dividida. Las dos partes o facetas del individuo resultan tanto excluyentes como necesarias, lo que constituye la paradoja que somete a este individuo a una crisis de identidad. Hay, en principio, un deseo de eliminar al otro, al extraño, según una necesidad de coherencia y uniformidad, y ante la posibilidad de ser eliminado por él; pero, al mismo tiempo, se descubre que ese otro no puede ser eliminado, bien porque es algo consustancial a uno mismo o bien porque es un producto necesario, surgido de una serie de circunstancias históricas y sociales.

En este punto es donde pueden aplicarse algunas de las ideas de Zygmunt Bauman para ejemplificar este conflicto. Como punto de partida, la opción de la eliminación del otro puede relacionarse con las ideas de pureza, limpieza y contaminación apuntadas, que tienen que ver, en términos sociológicos y políticos, como señala Bauman, con la noción de orden, coherencia y adecuación:

La pureza constituye un ideal: una visión de la condición que todavía hay que crear, o de esa condición que hay que proteger diligentemente de los peligros reales o imaginarios. [...] La pureza equivale a una visión de las cosas según la cual éstas se sitúan en posiciones diferentes a las que ocuparían si no se vieran instigadas a cambiar de ubicación, empujadas, arrastradas o azuzadas; y constituye una visión de orden - es decir, de una situación en la que cada cosa no se encuentra más que en su lugar adecuado - . . ...] Lo opuesto a la pureza - la suciedad, la inmundicia, los "agentes contaminantes" - son las cosas "fuera de lugar". No es la cualidad intrínseca de las cosas lo que las convierte en "suciedad", sino únicamente su ubicación; o más exactamente, su ubicación dentro del orden de cosas concebido por los buscadores de pureza. ${ }^{51}$

Desde esta identificación de lo puro con el orden, aquello que se sale de lugar, que se mueve y que desestabiliza un determinado estado de cosas se convierte, automáticamente, en

\footnotetext{
50 José María Micó, Caleidoscopio (Madrid: Visor, 2013), 19.

${ }^{51}$ Bauman, La postmodernidad, 2001, 14. Las cursivas son del original. www.enclavesdelpensamiento.mx https://doi.org/10.46530/ecdp.v0i30.438
} 
impureza o suciedad, como ocurre con el caso de los extraños, tal como continúa desarrollando el mismo autor:

Si la "suciedad" es un elemento que contraviene el propósito de los esfuerzos ordenadores y la suciedad que actúa por sí misma, se mueve por sí misma y se controla a sí misma constituye un elemento que desafía la propia posibilidad de efectividad de tales esfuerzos, entonces el Extraño es la personificación misma de este tipo de suciedad. ${ }^{52}$

Según estas ideas, eliminar la amenaza, la suciedad y las impurezas, equivaldría a recuperar - o imponer - el orden y la coherencia, y a poner o volver las cosas a su lugar, algo que, tanto a nivel social (macro) como individual (micro), constituye, en realidad, un ideal o una utopía irrealizable.

Bauman recuerda en este sentido las utopías de pureza social presentes en la construcción de los modernos estados totalitarios, que implicaban la eliminación de todo lo diferente y lo extraño:

Las utopías modernas diferían en muchas de sus prescripciones pormenorizadas, pero todas coincidían en que el "mundo perfecto" sería uno que se mantendría siempre idéntico a sí mismo, un mundo en el que la sabiduría adquirida hoy continuaría siendo sabia mañana y pasado mañana y en el que el savoir-faire cotidiano alcanzado conservaría por siempre su valor. El mundo perfilado en las utopías era también, como cabría de esperar, un mundo transparente: un mundo en el que nada oscuro e impenetrable obstaculizase la vista; un mundo sin nada que malograra la armonía; sin nada "fuera de lugar"; un mundo sin "suciedad"; un mundo sin "extraños". ${ }^{3}$

Creo que esta misma idea puede aplicarse al problema de la identidad individual que, en muchos casos, tal como ocurría con esos estados totalitarios y su idea de orden y pureza, y continuando con la equivalencia entre cuerpo social y cuerpo individual propuesta a lo largo de esas páginas, se pretende o se anhela como una identidad coherente y homogénea, sin suciedad y sin fisuras.

Algo así se sugiere, por ejemplo, en el poema en prosa "Escribir", de José María Micó, en el que puede apreciarse la insistencia en las ideas de invasión o posesión negativa ya analizadas, materializadas en este caso en la forma animal de un sapo. Estas ideas se asocian aquí con los rasgos de esa suciedad, enfermedad o corrupción a la que alude Bauman, que suponen una amenaza para la integridad de quien habla y de la que intenta librarse o limpiarse sin conseguirlo:

52 Ibid., 19.

${ }^{53}$ Ibid., 21.

www.enclavesdelpensamiento.mx

https://doi.org/10.46530/ecdp.v0i30.438 
un fuego intenso y lento, $[\ldots]$ se está comiendo mis vísceras, martillea en mi cabeza, late henchido en mis entrañas como papada de sapo, y supura un verde hedor enfermo, un apestoso verdor moribundo que intento sacudirme y me salpica la cara y me embadurna las manos, y yo me froto y me froto y se convierte en un azufre que me come la carne. ${ }^{54}$

Al igual que la utopía de un mundo perfecto de la Modernidad a la que alude Bauman, en la que todo permanece idéntico a sí mismo, la idea de una identidad coherente, continua y unitaria, puede pensarse también, como ya se dijo, como una utopía; algo irreal, inexistente e inalcanzable. Por un lado, porque las identidades rara vez son unitarias, uniformes y puras, sino múltiples, multiformes y variadas. Y, por otro, porque como el mismo autor señala, la época actual no favorece ni necesita una identidad permanente y constante, sino una identidad más adecuada a la posmodernidad, que sea flexible, cambiante y líquida:

El anhelo de identidad procede del deseo de seguridad que, en sí mismo, es un sentimiento ambiguo. Por muy estimulante que pueda ser a corto plazo, por muy llena de promesas y de indecisas premoniciones sobre una experiencia todavía sin probar, flotar sin apoyos en un espacio pobremente definido, ubicados machacona y fastidiosamente "entre la espada y la pared", se convierte a largo plazo en un enervante estado propenso a la ansiedad. Por otro lado, una posición inamovible entre infinitud de posibilidades, tampoco es una perspectiva muy halagüeña. En nuestros modernos tiempos líquidos, donde el héroe popular es el individuo sin trabas que flota a su libre albedrío, "estar fijo", "estar identificado" inflexiblemente y sin vuelta atrás tiene cada vez peor prensa. ${ }^{55}$

El problema de la crisis de la identidad parece suponer, así, un problema irresoluble, ya que ninguna de las dos opciones posibles resulta satisfactoria. Lo mismo que ocurría en muchos de los textos poéticos analizados, Bauman relaciona la identidad con la idea de lucha o batalla inherente y alude a la continua tensión que existe entre el deseo de su fijeza o permanencia y el miedo a su disolución, en términos muy cercanos a los que aparecen en los poemas:

La identidad, digámoslo claramente, es "un concepto calurosamente contestado". Donde quiera que usted oiga dicha palabra, pueda estar seguro de que hay una batalla en marcha. El hogar natural de la identidad es un campo de batalla. La identidad solo vuelve a la vida en el tumulto de la batalla; se adormece y queda en silencio cuando el fragor de la batalla se desvanece. Por lo tanto, no se puede evitar impedir lo uno y lo otro. Tal vez pueda ser deseada sin parar (y lo es normalmente por filósofos que luchan por elegancia lógica), pero no puede ser obviada sin parar y todavía menos abolida sin parar en la práctica humana. La "identidad" entraña una lucha simultánea contra la disolución y la fragmentación; una intención de devorar y, al mismo tiempo, una resulta negativa a ser comido... ${ }^{56}$

\footnotetext{
${ }^{54}$ Ibid., 46.

${ }^{55}$ Bauman, Identidad, 68-69.

${ }^{56}$ Ibid., 165. Las cursivas son del original.

www.enclavesdelpensamiento.mx

https://doi.org/10.46530/ecdp.v0i30.438
} 
Desde estas últimas líneas pueden entenderse quizá mejor las ideas de persecución, precariedad y amenaza que aparecen en muchos de los poemas contemporáneos, así como las acciones complementarias de "devorar" y "ser comido", en las que se pueden reconocer figuras y actores que resultan ya familiares tras la lectura de los poemas.

Según esto, la fragmentación, la dispersión, la escisión parecen resultar una constante, como lo es también, el deseo de unificación. Como menciona Vicente Luis Mora al final de su estudio, a pesar de la escisión "hay una forma de yo que sigue aspirando a la unidad; consciente o no de su carácter ficcional, anhela la reconciliación de las partes". 57 Sin embargo, no cabe más que admitir, como el mismo crítico señala, que el yo no es ni uno, ni doble ni trino, sino que su constitución se asemeja más a un "bosque", que es o puede ser distintas formas y admitir distintas representaciones: "Nuestro yo boscoso se forma a lo largo de los años y se adensa ocupando llanos, colinas y valles; ninguno de estos árboles individualmente tomado somos nosotros; nosotros somos la suma, el bosque entero, la proliferación". 58

\section{Conclusiones}

Un gran número de poemas españoles contemporáneos representa la falta de reconocimiento de un sujeto que se percibe a sí mismo como si fuera otro. Esta otredad, entendida de manera negativa, en lo que tiene de peligro o amenaza para la integridad, se manifiesta en los textos a través de figuras como la del extraño o lo extraño deshumanizado. Casas en ruinas, abismos, pozos, reptiles, lagartijas, murciélagos, lobos, bosques misteriosos, minotauros y monstruos, no son sino formulaciones o materializaciones del rechazo a lo diferente - tanto dentro como fuera de uno mismo- y del miedo ante la amenaza que esta diferencia supone para la idea de unidad, homogeneidad y pureza de un individuo que se siente escindido o fracturado.

Lo individual y lo colectivo resultan equiparables, como se adelantó al inicio, y se ponen en relación ideas y conceptos estudiados por la psicología con otros propios de la sociología, la antropología y la filosofía. Nociones como la de higiene ontológica, ideal de

\footnotetext{
${ }^{57}$ Mora, El sujeto boscoso, 306.

${ }^{58}$ Ibid., 308.

www.enclavesdelpensamiento.mx

https://doi.org/10.46530/ecdp.v0i30.438
} 
pureza y utopía o identidad unitaria pueden aplicarse tanto al individuo contemporáneo como a la sociedad en la que vive y a sus procesos de transformación.

Muchos de estos poemas se centran en la idea del conflicto, la tensión o la lucha entre las partes conformadoras de la identidad, ya se entienda esta como una tensión inherente o consustancial al individuo o como una tensión histórica y temporal, derivada de la época contemporánea.

Los textos manifiestan la violencia que ejerce el sujeto contra sí mismo como intento de solucionar esa tensión o brecha interior, mostrando las distintas posibilidades o fases de un proceso que oscila entre la simple mención o reconocimiento de esa tensión, su desarrollo o intensificación, o finalmente su culminación, con la escisión o separación del individuo. Se trata de la tensión entre el ser y el no ser, entre el aparecer y el desaparecer, tanto a nivel individual como colectivo, que tan bien ejemplifica el poema "Yo, o mi idea de yo", de Josep María Rodríguez. En este poema, el hablante registra esa tensión o esa ambivalencia en los siguientes términos: "a ratos me construyo", "a ratos me derribo", y concluye con una gráfica imagen que resume la tensión analizada en páginas anteriores: "como un niño que nace/ en un barco que se hunde". 59

La ficción que construyen los poemas da cuenta de un estado de mundo en un momento determinado y de las crisis y conflictos que afectan a los individuos que viven en él, al tiempo que permite formular o expresar la paradoja que existe entre el deseo o la necesidad de una identidad única o unitaria y su imposibilidad, ofreciendo temporalmente la fantasía de su resolución.

\footnotetext{
59 Josep María Rodríguez, "Yo, o mi idea de yo", en Jesús Aguado (ed.), Fugitivos: antología de la poesía española contemporánea (Madrid: FCE, 2016), 294. 


\section{Bibliografía}

Aguado, Jesús. (ed.). Fugitivos: antología de la poesía española contemporánea. Madrid: FCE, 2016.

Bargalló, José. (ed.). Identidad y alteridad: aproximación al tema del doble. Sevilla: Alfar, 1994.

Bauman, Zygmunt. La postmodernidad y sus descontentos. Madrid: Akal, 2001.

Bauman, Zygmunt. Identidad. Madrid: Losada, 2005.

Borges, Jorge Luis. El Aleph. Buenos Aires: Losada, 1949.

Cano Ballesta, Juan. (ed.). Poesía española reciente (1980-2000). Madrid: Cátedra, 2001.

Cuenca Tudela, Dolors. La ficcionalización del sujeto poético en la poesía española de la postmodernidad. Valencia: Universidad de Valencia, 1998.

De Villena, Luis Antonio, (ed.). La lógica de Orfeo: antología. Madrid: Visor, 2003.

García, Eduardo. No se trata de un juego. Granada: Diputación Provincial de Granada, 2004.

García Martín, José Luis. La poesía figurativa: crónica parcial de quince años de poesía española. Sevilla: Renacimiento, 1992.

Girard, René. La violencia y lo sagrado. Barcelona: Anagrama, 1983.

Graham, Elaine. Representations of the Post/Human: Monsters, Aliens and Others in Popular Culture. New Jersey: Rutgers University Press, 2002.

Izaola, Amaia, e Imanol Zubero. "La cuestión del otro: forasteros, extranjeros, extraños y monstruos". Papers, 100, núm. 1 (2015): 105-129.

Lanz, Juan José. "La joven poesía española al fin del milenio: hacia una poética de la postmodernidad". Letras de Deusto, (1995): 173-206.

Mainer, José Carlos, (ed.). El último tercio de siglo: antología consultada de la poesía española (1968-1998). Madrid: Visor, 1999.

Martín-Estudillo, Luis. "El sujeto (a)lírico en la poesía española contemporánea y su trasfondo barroco". Hispanic Review, 73, núm. 3 (2005): 351-370.

Martínez, Érika. "Valores portátiles: el sujeto bajo crítica”. En Luis Bagué Quílez y Alberto Santamaría (Eds.), Malos tiempos para la épica: Última poesía española (20012012). Madrid: Visor, 2013.

Micó, José María. Caleidoscopio. Madrid: Visor, 2013. 
Mora, Vicente Luis. El sujeto boscoso: tipologías subjetivas de la poesía española contemporánea entre el espejo y la notredad (1978-2015). Madrid y Frankfurt: Iberoamericana-Vervuert, 2016.

Munárriz, Jesús (ed.). Veinticinco poetas españoles jóvenes. Madrid: Hiperión, 2003.

Oliván, Lorenzo. Puntos de fuga. Madrid: Visor, 2001.

Rimbaud, Arthur. Iluminaciones. Cartas del vidente. Madrid: Hiperión, 1995.

Rodríguez, Josep María (ed.). Yo es otro: autorretratos de la nueva poesía. Barcelona: DVD, 2001.

Valverde, Fernando. Los ojos del pelícano. Madrid: Visor, 2010.

Žižek, Slavoj. Visión de paralaje. Buenos Aires: FCE, 2006. 